\title{
Clay makabaye in the far north Cameroon: study chemical and mineralogical depth
}

\author{
F. Tchangnwa Nya ${ }^{1,2} *$, E. Ngale Haulin ${ }^{1}$, E. Yanne ${ }^{1}$, C. Kabe ${ }^{1}$, B. Touogam Touolak ${ }^{1}$, J. M. Ndjaka ${ }^{3}$ \\ ${ }^{I}$ Department of Materiel Processing, Architecture and Habitat, Higher Institute of the Sahel \\ ${ }^{2}$ Department of physics, Faculty of Sciences, University of Maroua \\ ${ }^{3}$ Department of Physics, Faculty of Sciences, University of Yaoundé I \\ *Corresponding author E-mail: nyafridolin@yahoo.fr
}

Copyright ()$^{2} 2015$ F. Tchangnwa Nya et al. This is an open access article distributed under the Creative Commons Attribution License, which permits unrestricted use, distribution, and reproduction in any medium, provided the original work is properly cited.

\begin{abstract}
This scientific work was initiated as a result of many concerns facing most researchers on the nature, properties and characteristics of the clay materials northern Cameroon. Including the city of Maroua in the Far North Region Cameroon. The specific case of Makabaye is indeed the object of this science. This work can serve as a guide, and why not valuable source of information useful to a deeper understanding of the chemical and mineralogical characteristics of Makabaye clay. Judicious use of the results of this work may also lead to the formulation of the products in terracotta, with a valuation of its clays in the cosmetics industry, real estate, pharmaceuticals, and purification of vegetable oils. To achieve our results, we basically made of chemical and mineralogical analysis in the laboratory, along with a team of sworn laboratory for major tests we have done. In particular, it is the XRD X-ray analysis for the determination of mineral elements, and finally, the geochemical analysis by X-ray fluorescence, to better identify the specific chemical characteristics of the clay. We believe the views of the results obtained, absorbent properties of the clay materials, properties that can be put to good use in the purification of vegetable oils and waste water treatment.
\end{abstract}

Keywords: Clay Mineralogy; Absorbing Properties; Clay Materials; Makabaye (Maroua).

\section{Introduction}

In the context of sustainable development and technological innovation as the world is booming in the field of futuristic research, the study of clay and its multiple properties for various applications, and in many damaged areas of life daily, and therefore already appears as an imperative. It is in this wake and this futuristic vision that is part of this study. It has several scientific purposes and would achieve full valorisation clay of the study area, for local sustainable development. Recognised for its uniqueness and specificity, Makabaye clay materials in Maroua, captivated our curiosity. Because we dare to believe that exploitation of clay in this area, for a valorisation in many sectors of the cosmetics, pharmaceutical, toxic waste treatment, would prove beneficial and promising for the International Association for Study of Clay (AIPEA) and the Clay Mineral Society (CMS). The majority of soils in the northern part of the Far North Cameroon are renowned for their clay content. These soils are fersiallitic effect, powdered clay and sandy dune somewhat [1-3]. The main chemical and mineralogical minerals that contain Makabaye clay materials indeed justify its use of clay in various fields of the chemical industry. It is also a constant concern for sustainable development of the Far North Region Cameroon that is part of this study. She would encourage potential national and international investors, and why not the entire scientific community, to focus on the specific Maroua clay in particular, and the Far North Region Cameroon clay in general. 


\section{Mineralogy of clay}

Clay has a huge economic value in the world. By their various chemical and mineralogical properties, they can be used directly or with some treatments in the industry after their extraction [4-6].

\subsection{Clay minerals}

Because of their various physical, chemical and mineralogical properties (adsorption and absorption of various ions and molecules, adhesion, emulsion, malleability, resistance ...), clay has been used since antiquity in the manufacture of pottery rudimentary. Clay is not defined and a single material, but they are composed of complex combinations of minerals. They are hydrated aluminosilicates of a sheet structure called phyllosilicates [5-8].

\subsection{Clay minerals: classification and potential industries valuation}

According to the classification of clay, we distinguish several categories according to their characteristics and specificities. These include: carbonates (limestone, dolomite, magnetite), clay (kaolin, betonies, smectite, vermiculite, ordinary clay, sandy clay), evaporates (gypsum, halite, apatite). These all have a sedimentary origin, and various ceramic applications, metalworking, cosmetics, paints, pharmacology, environmental protection, refining, food processing, chemicals [5-14]. Moreover, we also distinguish magmatic origin of clay minerals (granite, diorite, feldspar, quartz, basalt, pozzolan, perlite), metamorphic (marble, graphite, talc), and finally materials clay from hydrothermal deposits and diagenetic (barite, fluorite, zeolite). These are especially used in chemical industry, metallurgy, including various fields of sanitation (wastewater) and environmental protection.

\section{Main clay}

We present here the clay commonly used. The most important being clay: kaolinite, smectites, illite, chlorites, and vermiculites [15-26].

\subsection{Kaolinite}

Its structure is stable since the water cannot be adsorbed only around the particles, and this is not swellable clay. Kaolinite is common in clay sediments from the alteration of feldspar-rich acidic rocks (granites, for example). It presents a high alumina content (46\%), and shows excellent properties of plasticity. With low shrinkage during drying and cooking, this clay requires high firing temperatures, and it is quite refractory after cooking. Minor structural changes give nacrite halloysite and dickite [15-26].

\subsection{Smectite}

It is characterised by the large interchange of ions $\left(\mathrm{Mg}^{2+}, \mathrm{Fe}^{3+}\right)$, and thus their ability to bind water in the interlayer space. The crystals are usually very thin. Within this structure and the capacity of absorption of water into the interlayer space, derive their unique properties of high plasticity, high water absorption, shrinkage / swelling, absorbing power and binder. Saponites, nontronite and beidellites are varieties of smectites [15-26].

\subsection{Illites}

The most common clay mineral in the clay also belongs to the group three layers with potassium mica, and is called illite. Illite composition is variable depending on the forming conditions. It has a limited capacity for exchange, and the interlayer space remains constant. It contains a little less than potassium, but more water as muscovite. It is sometimes said that illite is a "hydro-mica." The presence of potassium, which plays the role of flux, may lower the incipient melting temperature to $1050^{\circ} \mathrm{C}$. Illite provides the plasticity of the material [15-26].

\subsection{Chlorites}

They are quite common in clay for terracotta. It should be noted that there are many compounds, a little less common, very similar in their chemical compositions and structures, and that the above compounds are often mixed. They are known for their leaf shapes, and their slippery absorbing properties [15-26]. 


\subsection{Vermiculites}

They are a close family of the smectite, but they are characterised by a deficit much larger load. They are mostly phyllosilicates. The charge deficit is mainly due to tetrahedral substitutions, and compensation is provided in the interlayer space by captions (mainly $\mathrm{Mg}^{2+}$ ) and water layers [15-26].

\section{Main physico-chemical and mineralogical characteristics sought in clay}

The physico-chemical and mineralogical characteristics sought in clay for use in the production of the expanded clay aggregates are: a relatively high plasticity, with high fines content. A high content of preferably layered silicates (mica or illite), and greater than $40 \%$ is preferred; the kaolinite content, however, should be low [22-26]. It should be emphasised that the above natural plasticity of a material is a characteristic property of the fine particles in this case the clay in relation to the existence of water adsorbed layers. Thus, Atterberg limits and in particular the plasticity index of a soil varies not only with the size of its clay fraction but also with the nature of the clay minerals and adsorbed cations. The highest values of this index are obtained with montmorillonite and especially those responsible for the sodium cation [27-34].

The degree of crystallinity among the parameters sought for valorisation of kaolinite clay in particular the composition of the pulp. Kaolinitic clay have an unmodified semi-booster natural gums character; this power is even greater than clay used are pure and well crystallised. Kaolinite content supports the semi-reinforcing grades whereas quartz and mica it unfavorable [35-42].

\section{Materials and methods}

It is therefore essential to understand the clay material characterisation, that is to say, to analyse the properties [35, 36]. Many techniques exist for characterising materials and are mainly based on different chemical and mineralogical basic principles [22-24]. In this study, we used chemical characterisation (X-ray fluorescence, atomic absorption spectroscopy) and mineralogical (X-ray diffraction, infrared spectroscopy). Studies of the clay samples collected were mainly conducted in the laboratory.

\section{Results and discussion of chemical and mineralogical analyses obtained in the laboratory}

This is about to present the main results obtained in the laboratory. The discussion phase will be here to do a comparison of laboratory results with those contained in our literature review. Thereafter, we will draw conclusions about the profitability of Makabaye clay in diverse industry sectors.

\subsection{X-ray diffract metric analysis}

The principle of this method is based on the X-ray diffraction by the crystal lattice. This is a three-dimensional spatial distribution of an atomic unit. The general method involves bombarding the sample with X-rays from a metal anode, and which are first plugged by a divergence slit to produce a sub-parallel beam. This is directed at the sample at the angle $\theta$ and is diffracted when the conditions of the Bragg law are fulfilled [39-42].

\subsubsection{Sample preparation and procedure}

The finely ground to a particle size less than $75 \mu \mathrm{m}$ sample is deposited on a sample holder in hard plastic for analysis. The sample surface is flattened by pressing with a glass plate, in order to stabilise the particles during rotation of the sample holder which is fixed to 15 turns per minute. The scan angle varies between 5 and 60 degree. The tube and detector burp simultaneously and thus constitute the technique developed by Bragg-Brentano. The conditions of acceleration of electrons in the tube are $40 \mathrm{KV}$ and $40 \mathrm{~mA}$.

\subsubsection{Results and interpretations}

Mineralogical analyses obtained from Figure 1, we have varying proportions, composed mainly of quartz, feldspar, kaolinite, hematite, palygorskite, as goethite and clay minerals. The various inter-reticular distances of the main minerals are presented in Table 1 [26-33]. 


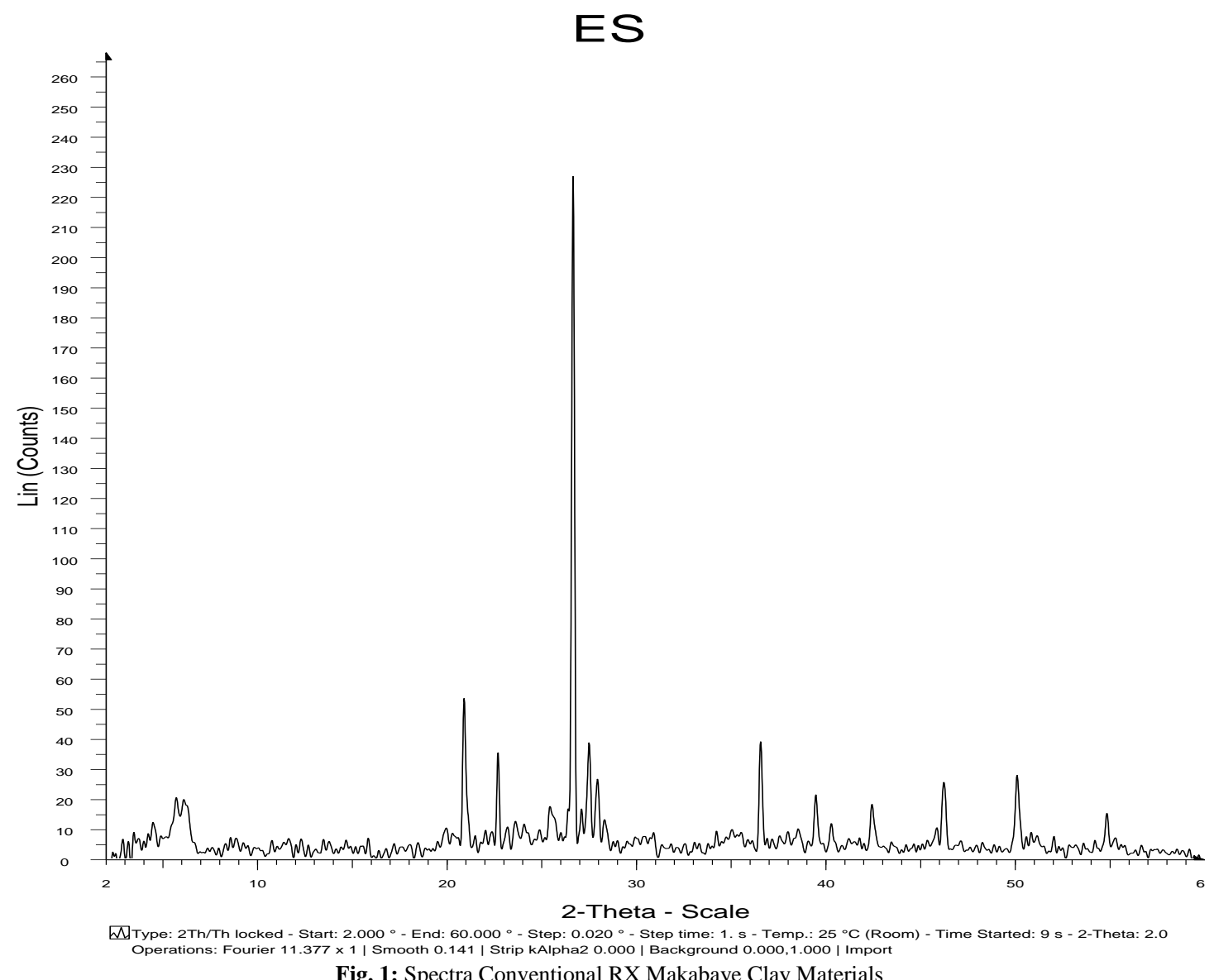

Fig. 1: Spectra Conventional RX Makabaye Clay Materials

Table 1: Major Minerals Present in the Makabaye Clay Materials

\begin{tabular}{ll}
\hline Minerals & Distance inter mineral lattice d $(\AA)$ \\
\hline chlorite & 4,$77678 ; 4,76636,4,71106 ; 4,68517 ; 4,66291$ \\
feldspars & 3,$2571 ; 3,23877 ; 3,23161 ; 3,22047$ \\
goethite & 2,$46742 ; 2,45591 ; 2,44679 ; 2,43781$ \\
hematite & 2,$68373 ; 2,694472 ; 2,71074 ; 2,71859$ \\
kaolinite & 7,$26006 ; 7,20634 ; 7,08151 ; 7,00508$ \\
magnetite & 2,$53615 ; 2,53222 ; 2,51983 ; 2,51336$ \\
palygorskite & 10,$48888 ; 10,65503 ; 10,74764$ \\
pyrite & 1,$62982 ; 1,62663 ; 1,62371$ \\
quartz & 3,$34549 ; 3,29379 ; 3,28063 ; 3,2571$ \\
sepiolite & 12,$61483 ; 12,36497 ; 12,14675$ \\
\hline
\end{tabular}

Kaolinite is a layered silicate ceramic holder favorable properties. This mineral can be formed by hydrolysis or plagioclase feldspar, and mica constituent of sandstone due to the involvement of meteoric waters in a tropical climate and warm [14], [15]. The existence of this feldspar technical interest since the plastic paste formed by mixing the clay with water, contracts during drying and heating above. These withdrawals are minimised by non-plastic components (degreasing), the feldspars also play the role of fondant. This promotes the occurrence of a viscous phase, at a low melting point during the heat treatment. And thus helps to reduce the porosity of the room, while improving the mechanical properties of the latter. The presence of associated goethite titania in these natural products is a significant added value in the red dye and / or yellowish end products [14], [34- 36].

\subsection{Geochemical analysis by $x$-ray fluorescence}

The analytical technique uses X-ray fluorescence of the physical phenomena have been discovered and developed in the field of quantum physics, which the photoelectric effect, spontaneous emission and diffraction of X-rays here, it excites the sample to be analysed with a standard radiation (with a biasing X-ray tube), and the re-emitted by the sample [3942] own radiation are analysed. 


\subsubsection{Sample preparation and procedure}

X-ray fluorescence produced by equipment type Bruker S4 Pioneer wavelength dispersive WDS available in the laboratory of MIPROMALO was used for the determination of major elements in the sample. The sample is ground to a particle size less than 75 micrometers. 12 grams were removed and then mixed with a cellulosic powder not detectable by X-ray fluorescence binder. With the mixture, a pellet of $35 \mathrm{~mm}$ in diameter and $0.5 \mathrm{~mm}$ thick is pressed, and then introduced into the spectrometer for analysis. In addition $5 \mathrm{~g}$ of the ground sample is placed in a cup which is heated to $800^{\circ} \mathrm{C}$ in order to determine the loss on ignition, which corresponds to the percentage value of the amount of organic matter contained in the sample. The values of inorganic element amounts determined by the spectrometer are added to the value of the loss on ignition of the sample to obtain a total amount close or equal to $100 \%$. The detection limit of the spectrometer for most chemical elements is greater than $100 \mathrm{ppm}$, trace values are chemical elements found in the sample but which cannot be quantified precisely. In order to determine the loss on ignition (LOI or MOU), the sample was calcined at $950^{\circ} \mathrm{C}$; is added an amount of the pellet to obtain Spectroflux borax.

\subsubsection{Results and interpretations}

Geochemical analysis by X-ray fluorescence revealed the mass concentrations of various oxides in the Makabaye clay materials. This is what we illustrated in Table 2.

Table 2: Overview of Oxides and Their Concentrations in Makabaye Clay Materials

\begin{tabular}{ll}
\hline Oxides & Mass Concentrations $(\%)$ \\
\hline $\mathrm{Al}_{2} \mathrm{O} 3$ & 11,97 \\
$\mathrm{BaO}$ & 0,096 \\
$\mathrm{CaO}$ & 1,16 \\
$\mathrm{Fe}_{2} \mathrm{O}_{3}$ & 2,773 \\
$\mathrm{~K} 2 \mathrm{O}$ & 3,924 \\
$\mathrm{MgO}$ & 0,656 \\
$\mathrm{MnO}$ & 0,0513 \\
$\mathrm{Na} 2 \mathrm{O}$ & 0,539 \\
$\mathrm{P} 2 \mathrm{O} 5$ & 0,045 \\
$\mathrm{Rb} 2 \mathrm{O}$ & 0,0142 \\
$\mathrm{SiO} 2$ & 74,23 \\
$\mathrm{SrO}$ & 0,0263 \\
$\mathrm{TiO} 2$ & 0,79 \\
$\mathrm{ZnO}$ & 0,005 \\
$\mathrm{ZrO} 2$ & 0,0600 \\
$\mathrm{P.E}$ ou LOI & 3,66 \\
$\mathrm{Total}$ & 99,9998 \\
\hline
\end{tabular}

Examining the percentages of major elements contained in Table 2, it emerges that the silica content of $74.23 \%$, this suggests a ground rewrite. In addition, the percentages of the silica samples are relatively high for Makabaye be ranked among the plastic clay. [15] It is also found that the alumina content is $11.97 \%$, this makes it possible to store these materials from the sand-clay products. These materials also contain a small content of $\mathrm{T}_{\mathrm{i}} \mathrm{O}_{2} 0.79 \%$ and iron oxide equal to $2.773 \%$. They can therefore be used as raw resources for the manufacture of brick red, orange or yellow. The $\mathrm{K}_{2} \mathrm{O}$ content being $0.539 \%$ and $3.924 \%$ for $\mathrm{Na}_{2} \mathrm{O}$, suggest the presence of alkali feldspar and mica up these rocks. Concentrations of alkaline earth $(\mathrm{CaO}$ and $\mathrm{MgO})$ are quantitatively and significantly too low $\leq 1.16 \%$. The analysed material is devoid of carbonate components. The loss on ignition of Makabaye clay materials is 3.66\%, which confirms the presence of low organic matter, and interstices retaining some water [37-41].

\section{Conclusion}

Clay materials are therefore basic raw materials in the manufacture of ceramic products manufactured whose main sectors are: bricks and tiles; tiles for floors and walls; ornamental or domestic ceramics; refractory products; fixtures; technical ceramics (insulators, capacitors, filters, biomedical products, ...); vitrified clay pipes; expanded clay and inorganic abrasive aggregates. Ceramic technology, clay used must meet the requirements particle size, chemical and / or mineralogical order to obtain good quality products. Kaolinitic clay for example, are popular because of their relatively well-known properties, significant plasticity, low drying shrinkage, the absence of interlayer swelling and coloring slightly marked shards. Various other but not dosed clay or synthetic natural substances and adjuvants (additives) are currently used in the manufacturing processes of some ceramics [15-41]. 
The mineralogical composition of these materials is dominated by kaolinite, quartz, palygorskite, goethite and chlorite. From the chemical standpoint, these materials are characterised by a silica content: $74.23 \%$; Alumina: 11.97\%; ferric oxide and titanium oxide, 0.79 and $2.773 \%$; less than $2 \%$ of alkali metal oxides; less than $1.16 \%$ alkaline earth oxides; heavy metals ( $\mathrm{Sr}, \mathrm{Rb}, \mathrm{Zr}, \mathrm{Zn}$ ) too low (below $0.2 \%$ ), and a loss on ignition of $3.66 \%$. Clay materials would Makabaye products inheritance surrounding hilly areas that have sedimented in the heart of the alluvial plain of the river under fluvial conditions. We affirm certitude that these materials can be judiciously used in various sectors of the chemical industry, cosmetic, metal, cement, and pharmacology as well as for the treatment of toxic wastes.

\section{References}

[1] Gavaud, M., Brabant, P., (1985) République du Cameroun. Carte des Ressources en Terres. Provinces du Nord et de l'Extrême-Nord. Legend., ORSTOM et IRA

[2] Seignobos C., Iyébi Mandjek O., Inc-Ird, 171 p. Page 9. 129 ... Synthèse nationale des analyses de terre : période 1990-1994 par C. Walter, C. Schvartz, B. Claudot, P. Aurousseau et T. Bouedo, avec le concours du Ministère de l'Agriculture et de la Pêche.

[3] Seignobos, Christian \& Thys, Éric, eds.--Des taurins et des hommes. Cameroun, Nigeria. Paris, Éditions de l'Orstom, 1998, 400 p

[4] A. E. Aksu et al. (2002): Origin of late glacial-Holocene hemipelagic sediments in the Aegean Sea: clay mineralogy and carbonate cementation, Elsevier.

[5] Adamo, P; Oudka, S; Wilson, MJ and Mc Hardy, W.J. (1996): Chemical and mineralogy forms of $\mathrm{Cu}$ and Ni in contaminated soils from Sudbary Mining and Smelting Region, Canada. Environ Pol. 91 (I): pp.II-19.

[6] Aswathanarayana, U (1995): Geoenvironment: an introduction AA Balkema: pp 270.

[7] Baldi, M.; Negri. MC and Capodaglio, A.G. (1990): In: Metals speciation, separation and recovery. J.W. patterson. Passino eds., Lewis Publishers. Inc., Chelsa. MI, United States. pp. 377-392.

[8] Baptista Neto. J.A; Snitu, BJ. And McAllistes, JJ. (2000): Heavy metal concentration in surface sediments in near shore environment, Jurujuba Sound, Southeast Brazil. Environ. Pol. pp. 109: 1-19.

[9] Barth, T.F.W. (1961): Abundance of the elements, areal averages and geochemical cycles Gochim. Cosmochim Acta, 23: pp.I-8.

[10] Baskaran, M. and Somayanjulu, B.L.K. (1990): clay minerals distributions in dated Milliolites of the late Quarternary from Saurashtra and Kutch, Gujarat. J. of Geol. Soc. India (35(5), pp. 480-496.

[11] Baskaran, M.; Sarin, MM and Somayajulu, B.L.K. (1984): Composition of mineral fractions of the Narmada and Tapti estuarine particles and the adjacent Arahian sea sediments of Western India. Chern. Geol. 45: pp. 33-51. http://dx.doi.org/10.1016/0009-2541(84)90114-1.

[12] Berner R.A. (1971): Principles of chemical sedimentology McGraw Hills Publication, New York 240p.

[13] Berner, E.K. and Berner, R.A. (1987): The global wat $\sim$ r cycle. Geochemistry and Environment. Prentice hall; Englewood Cliffs, New Jercy 07632, 397p.

[14] Bhosle, NB; Dhargalkar, VK and Braganca, AM (1978): Distribution of some biochemical compounds in sediments of the shelf and slope regions of the West Coast ofIndia. Ind. J. Mar. Sci. 7, pp. 155-158.

[15] Bikshamaiah, G and Subramanian, V (1980): Chemical sediment mass transfer in Godavari River Basin in India, Journal of Hydrology, 46, pp. 331-342. http://dx.doi.org/10.1016/0022-1694(80)90085-2.

[16] Biscaye, P.E. (1965): Mineralogy and sedimentation of recent deep see clay in the Atlantic Ocean and adjacent seas and oceans, Geol. Soc. Am. Bull., 76: pp. 803-832. http://dx.doi.org/10.1130/0016-7606(1965)76[803:MASORD]2.0.CO;2.

[17] Bukhari, Sand Nayak, GN (1996): Clay minerals in identification of provenance of sediments of Mandovi estuary, Goa, west coast of India. Ind. J. Mar. Sci. 25, pp.34]-345.

[18] Cam bier, P. (1997): Evaluation of the mobility of toxic elements in contaminated soils. Anal Mag. 25, pp. 35-38.

[19] Carrol, D. (1970): clay minerals -a guide to their identification G.S.A. Spec. Pap 126, 80p.

[20] Chakrapani GJ and Subramanian V (1990): Preliminary studies of the geochemistry of the Mahanadi river basin, India, Chern. Geol., 81, pp. 241-253. http://dx.doi.org/10.1016/0009-2541(90)90118-Q.

[21] Chester, R. and Hughee, (1967): A chemical technique for the separation of ferromanganese minerals carbonate minerals and adsorbed trace elements from pelagic sediments. Chemical Geol. 2, pp. 249-262. http://dx.doi.org/10.1016/0009-2541(67)90025-3.

[22] Chiao, L.L. (1972): Selective dissolution of manganese oxides from soils and sediments with acidified hydroxylamine hydrochloride. Soil. Sci. Soc. Arne. Proc. 36, pp. 764-768. http://dx.doi.org/10.2136/sssaj1972.03615995003600050024x.

[23] Forstner, U. (1993): Metal speciation general concept and applications. International Journal of Analytical Chemistry, 51, pp. 5-23. http://dx.doi.org/10.1080/03067319308027608.

[24] Forstner, U. and Muller, G. (1974): Schwerme in Flussen and und see. Berlin: Springer. 255p.

[25] Galloway, IN; Schlesinger WH; Levy II H; Michaels A and Schnoor JL (1995): Nitrogen fixation: anthropogenic enhancement nvironmental response Global Biogeochemical Cycle, 9, pp. 235-252.

[26] Jackson, M.L. (1973): Soil chemical analysis, advanced course. Madison Winconsin. 530p.

[27] Jenne, F.A. (1968). Controls of $\mathrm{Mn}, \mathrm{Fe}, \mathrm{Co}, \mathrm{Ni}, \mathrm{Cu}$ and $\mathrm{Zn}$ concentrations in soils and waters: the significance of hydrous $\mathrm{Mn}$ and $\mathrm{Fe}$ Oxides. Am. Chern. Soc. Adv. Chern. Ser., 73. Pp.337-387.

[28] Johnson, A.G., J. Kelly. (1984): Temporal spatial and textural variation in the mineralogy of Mississippi river suspended sediments. J. Sed. Petrol. Vol. 54: No.1.

[29] Knedler, Ke; Glassby, GP and Preeman, AJ (1983): Mineralogy and geochemistry of iron in some recent continental shelf sediments off Goa. Ind. J. mars. Sci. 12, pp. 133-137.

[30] Konta, J (1985): Mineralogy and chemical maturity of suspended matter in major rivers sampled under the SCOPE! UNEP Project. In, ET Degens ET aI (eds) Transpori of carbon and minerals in major worid rivers Pt. j Mitt GeolPalaont Inst, Univ. Hamburg, SCOPE! UNEP, 58, pp. 569-592.

[31] Konta, J. (1988): Minerals in rivers. In (eds.) Degens E.T., Kempe, S., and Sathy Naidu, Transport of carbon and minerals in major world rivers, lakes and estuarine. Part 5, mil Geol-Palaont. Inst. Univ. Hamburg. SCOPEIUNEP, 66, pp.341-365.

[32] Krishnamurty, G.S.R.; Huang, P.M.; Van Rees, K.CJ; Kozak, L.M. and Rostad, H. P.W. (1995). Speciation of particulate-bound Cadmium of soils and its bioavailability. Analyst. 120, pp. 659-665. http://dx.doi.org/10.1039/an9952000659.

[33] Martin, J. M.; Nirel, P. and Thomas, A.G. (1987): Sequential extraction techniques: promises and problems. Mar Chern. 22, pp. 313-341. http://dx.doi.org/10.1016/0304-4203(87)90017-X

[34] Matricic, D., Kwokal, Z. and Branica, M. (1990): Distribution of Zn, Pb, Cd, and Cu between different size fractions of sediments. Sci. Trace metal geochemical associations in sediments from the culture bed of Anadara Granosa. Mar Pollut Bull. 28, pp. 319-323.

[35] Prabhaker Rao, P; Raju, A V and Nair, MM (1985): Geomorphology of Goa. In: Earth Res. of Goa Development (Seminar, GSI, Hydrabad, pp.583-588.

[36] Soman K. (1997): Geology of Kerala, published by Geological Society of India, Bangalore, India- 560 019, 280p. 
[37] Tack, F.M. G. and Valoo, M. G. (1995): Chemical speciation and fractionation in soil and sediment heavy metal analysis: A review. Int. J Envion. Anal Chern. 59, pp. 225-238.

[38] Whitney, P.R. (1975). Relationship of manganese -iron oxides and associated heavy metals to grain sizein stram sediments. J. Geochem Explor. 4, pp. 251-263. http://dx.doi.org/10.1016/0375-6742(75)90005-9.

[39] Yu, S., He, Z. L., Huang, C.Y., Chen, G.C. and Calvert, D.V. (2004: Copper fractionation and extractability in two contaminated variable charge soils. Geoderma, 123 pp. 163-175. http://dx.doi.org/10.1016/j.geoderma.2004.02.003.

[40] Zhang, J.G.; Huang, W.W. and Wary, Q. (1990): Concentration and partitioning of particulate trace metals in the Changjiang. Water, Air and Soil pollut. 52 pp. 57-70. http://dx.doi.org/10.1007/BF00283114.

[41] Ingersoll, K.V., P.F. Bullard., R.L. Frd., J.P. Grim., J8. Puckle and S.W. Sares. (1984): The effect of grain size on detrital modes: a test of the GazziDickinson Point Counting Method. J. Sed. Petrol. 54, pp. 103-116.

[42] Ittekkot, V. and S. Zhang. (1989): Pattern of particulate nitrogen transport in World Rivers. Global Biogeochemical cycles, Vol. 3(4), pp. 383391. http://dx.doi.org/10.1029/GB003i004p00383. 